\title{
KOMPARASI METODE ANFIS DAN FUZZY TIME SERIES \\ KASUS PERAMALAN JUMLAH WISATAWAN AUSTRALIA KE BALI
}

\author{
Ida Bagus Kade PUja Arimbawa K ${ }^{1}$, KetUt Jayanegara ${ }^{2}$, \\ I Putu EKa Nila Kencana ${ }^{3}$ \\ 1,2,3 Jurusan Matematika FMIPA Universitas Udayana, Bukit Jimbaran-Bali \\ e-mail: ${ }^{1} 28$ nateriver@gmail.com, ${ }^{2}$ ketut_jayanegar@yahoo.com, ${ }^{3}$ i.putu.enk@gmail.com
}

\begin{abstract}
This study compares the accuracy of forecasting using ANFIS and Fuzzy Time Series the number of Australian tourists to Bali. The data used in this study are data on the number of Australia tourists visit to Bali from the period January 2006 through December 2011. ANFIS consists of two stages of learning and testing phases. Least Squares Estimator is used to study the forward direction and Error Back Propagation learning is used in the reverse direction. Forecasting with Fuzzy Time Series is forecast to capture the pattern of previous data is then used to project the data to come. The results of comparison of both methods showed that the ANFIS method has a higher forecasting accuracy than the method of Fuzzy Time Series. Forecasting by using ANFIS method obtained AFER aqual to 9,26\% while the prediction using the method of Fuzzy Time Series obtained AFER aqual to $14,02 \%$
\end{abstract}

Keywords: ANFIS, Fuzzy Time Series, Forecasting, Australian Tourist Forecasting

\section{Pendahuluan}

Adaptive Neuro-Fuzzy Inference System (ANFIS) merupakan jaringan adaptif yang berbasis pada sistem kesimpulan fuzzy (fuzzy inference system). ANFIS dapat membangun suatu mapping input-output yang keduanya berdasarkan pada pengetahuan manusia (pada bentuk aturan fuzzy if-then) dengan fungsi keanggotaan yang tepat. Fuzzy time series merupakan proses dinamik dari suatu variabel linguistik yang nilai linguistiknya adalah himpunan fuzzy. Keunggulan pemodelan fuzzy time series adalah mampu memformulasikan suatu permasalahan berdasarkan pengetahuan pakar atau data-data empiris. Hasil peramalan dari kedua metode tersebut dibandingkan dengan tujuan mengetahui keakuratan hasil peramalan jumlah kunjungan wisatawan asal Australia ke Bali. Parameter yang dipakai sebagai perbandingan adalah AFER dan MSE dari masing-masing metode. Average Forecasting Error Rate (AFER) dan Mean Squared Error (MSE) sebuah estimator adalah nilai yang diharapkan dari error. Error yang ada menunjukkan seberapa besar perbedaan hasil estimasi dengan nilai yang akan diestimasi.

\footnotetext{
${ }^{1}$ Mahasiswa Jurusan Matematika FMIPA Universitas Udayana

${ }^{2,3}$ Staf Pengajar Jurusan Matematika FMIPA Universitas Udayana
} 


\section{Metode Penelitian}

Data yang digunakan dalam penelitian ini adalah data skunder. Data diperoleh dari Dinas Pariwisata Bali berupa data jumlah kunjungan wisatawan asal Australia ke Bali pada periode Januari 2006 - Desember 2010. Data akan diolah dengan menggunakan metode ANFIS dan Fuzzy Time Series. Adapun langkah-langkah dari kedua metode adalah:

\subsection{Adaptive Neuro Fuzzy Inference System (ANFIS)}

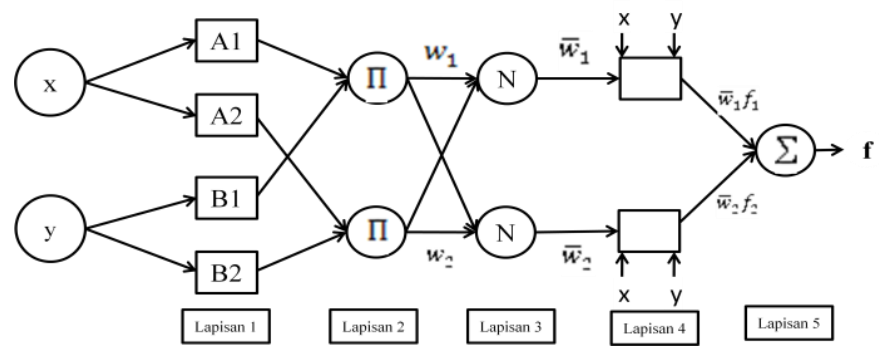

Gambar 1. Arsitektur ANFIS

Gambar 1 menunjukan Arsitektur ANFIS yang digunakan ialah Arsitektur ANFIS 5 Lapis dengan 2 masukan ( $x$ dan $y$ ) dan 1 keluaran $(f)$.

\section{Tahap Pembelajaran metode ANFIS [3]}

Lapisan 1: Setiap simpul pada lapisan ini adalah simpul adaptif dengan fungsi simpul

$$
\begin{aligned}
& O_{1 . \mathrm{i}}=\mu \mathrm{A}_{\mathrm{i}}(\mathrm{x}) \text { untuk } i=1,2 \\
& O_{1 . i}=\mu \mathrm{B}_{\mathrm{i}-2}(\mathrm{y}) \text { untuk } i=3,4
\end{aligned}
$$

Dengan $x, y$ adalah input ke- $i$ dan $\mu \mathrm{A}_{\mathrm{i}}$ dan $\mu \mathrm{B}_{\mathrm{i}-2}$ adalah nilai linguistik. $O_{1 . i}$ adalah derajat keanggotaan himpunan fuzzy $\mathrm{T}(\mathrm{A})=\left\{\mathrm{A}_{1}, \mathrm{~A}_{2}, \mathrm{~B}_{1}, \mathrm{~B}_{2}\right\}$ dengan $\mathrm{A}_{1}, \mathrm{~A}_{2}, \mathrm{~B}_{1}$, $\mathrm{B}_{2}$ merupakan variabel linguistik. Fungsi keanggotaan yang dipakai adalah fungsi gbell.

$$
\mu_{A_{i}}(x)=\frac{1}{1+\left[\frac{\left(x-c_{i}\right)^{2}}{a_{i}^{2}}\right]^{2 b_{i}}}
$$

Parameter $a, b, c$ pada parameter gbell dinamakan parameter premis.

Lapisan 2 : Operator perkalian dari aturan fuzzy pada simpul ini adalah AND.

$$
O_{2, i}=w_{i}=\mu A_{i}(x) \cdot \mu B_{i}(y) \text { untuk } i=1,2
$$

Dengan $\mathrm{w}_{\mathrm{i}}$ adalah derajat pengaktifan pada simpul ke $i$

Lapisan 3 : Pada simpul ke- $i$ dihitung rasio dari aturan derajat keanggotaan ke- $i$ dengan jumlah dari aturan derajat keanggotaan, sehingga dapat dirumuskan sebagai berikut:

$$
O_{3, i}=\bar{w}_{i}=\frac{w_{i}}{w_{1}+w_{2}} \text { dengan } i=1,2
$$


Dengan $\bar{w}_{i}$ adalah derajat pengaktifan ternormalisasi pada simpul ke- $i$

Lapisan 4 : Setiap layer pada lapisan ini adalah simpul adaptif dengan fungsi

$$
\text { simpul adalah } O_{4, i}=w_{i} f_{i}=w_{i}\left(p_{i} x+q_{i} y+r_{i}\right)
$$

Dengan $\{p i, q i, \quad r i\}$ adalah himpunan parameter yang disebut parameter konsekuen. Jika nilai dari parameter premis tetap.

Lapisan 5 : Merupakan simpul tunggal yang menghitung keluaran dengan menjumlahkan semua sinyal masukan $O_{5, i}=\sum \bar{w}_{i} f_{i}=\frac{\sum_{i} w_{i} f_{i}}{\sum_{i} w_{i}}$

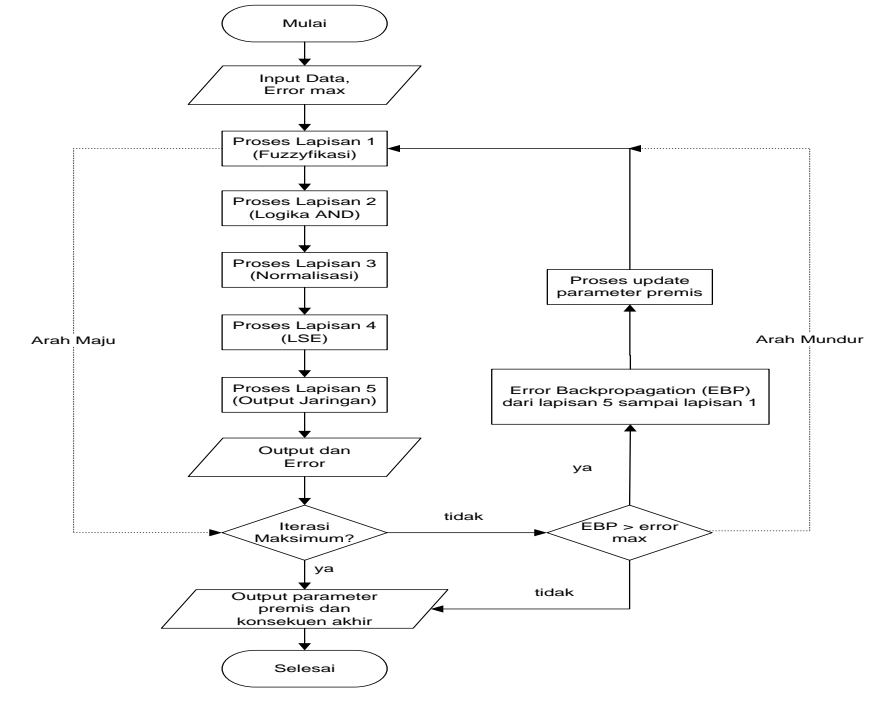

Gambar 2. Diagram Alir Tahap Pembelajaran Metode ANFIS

\section{Tahap Uji Coba ANFIS}

Proses uji coba hanya menggunakan arah maju dengan metode LSE. Masingmasing masukan akan diproses dengan nilai parameter premis dan konsekuen hasil proses pembelajaran. Untuk lebih jelas tentang proses uji coba, dibuat diagram alir seperti pada gambar 3.

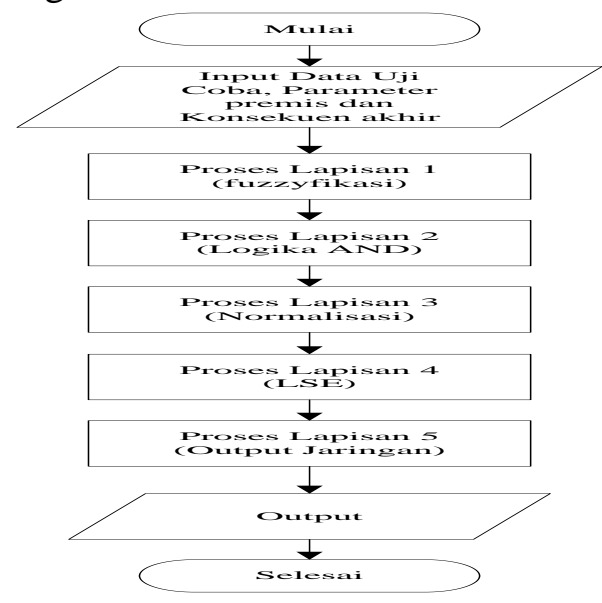

Gambar 3. Diagram Alir Tahap Uji Coba ANFIS 


\subsection{Fuzzy Time Series}

Adapun langkah-langkah peramalannya adalah sebagai berikut :

1. Data wisatawan yang berbentuk angka akan diubah dalam bentuk persentase, yaitu dengan menggunakan rumus $\frac{t_{j}-t_{j-1}}{t_{j-1}} \times 100 \%$

Dimana :

$t_{j}=$ jumlah wisatawan pada bulan yang diamati

$t_{j-1} \quad=$ jumlah wisatawan data pada bulan sebelumnya

2. Mendefinisikan himpunan semesta $U=\left[D_{\min }, D_{\max }\right]$ dan membaginya menjadi interval-interval $u_{1}, u_{2}, u_{3} \ldots . u_{n}$ dengan panjang yang sama. Pada tahap ini digunakan rumus sturges untuk menentukan panjang interval yang akan digunakan.

Rumus Sturges : $\mathrm{K}=1+3.322 \log (\mathrm{N})$

3. Menemukan interval yang memiliki sebaran data jumlah wisatawan tertinggi dan membaginya menjadi 4 sub-interval dengan jarak yang sama. Menemukan interval yang memiliki sebaran data jumlah wisatawan tertinggi ke 2 dan membaginya menjadi 3 sub-interval dengan jarak yang sama. Menemukan interval yang memiliki sebaran data jumlah wisatawan tertinggi ke 3 dan membaginya menjadi 2 sub-interval dengan jarak yang sama. Sedangkan interval-interval yang lainnya dibiarkan dan jika tidak ada sebaran data di dalam interval maka interval dihilangkan.

4. Mendefinisikan masing-masing himpunan fuzzy $A_{i}$ berdasarkan interval yang sudah dibagi-bagi dan mem-fuzzy-kan data jumlah wisatawan dengan himpunan fuzzy $A_{i}$ dinotasikan sebagai nilai linguistik dari perubahan persentase jumlah wisatawan dari bulan ke bulan yang diwakili oleh himpunan fuzzy. Fungsi keanggotaan gbell digunakan untuk mendefinisikan himpunan fuzzy $A_{i}$.

5. Defuzzyfikasi data fuzzy dengan menggunakan formula peramalan Fuzzy Time Series

\section{Hasil dan Pembahasan}

\subsection{Peramalan Metode ANFIS}

Penentuan awal parameter premis $\left(a_{1.1}, a_{1.2}, a_{2.1}, a_{2.2}, b_{1.1}, b_{1.2}, b_{2.1}, b_{2.2}, c_{1.1}, c_{1.2}\right.$, $c_{2.1}, c_{2.2}$ ) dibantu dengan menggunakan fungsi genparam pada MATLAB. Parameter premis dan konsekuen pada pembelajaran dengan data yang memiliki AFER dan MSE terendah akan digunakan dalam proses uji coba. 


\section{Proses Pembelajaran}

Diperoleh hasil pembelajaran untuk data set 1 : AFER $=9,29 \%$ dan MSE $=$ 10.666.699 data set 2: $\mathrm{AFER}=3,32 \%$ dan MSE $=2.350 .237$, data set 3: AFER $=2,53 \%$ dan $\mathrm{MSE}=3.478 .430$.

\section{Proses Uji Coba}

Untuk proses uji coba dengan mengambil parameter premis dan konsekuen pada proses pembelajaran untuk Data Set 3 pada iterasi ke 50000. Maka hasil yang diperoleh ialah:

Tabel 1. Hasil Peramalan ANFIS Tahap Uji Coba Tahun 2011

\begin{tabular}{|c|r|r|r|r|}
\hline Bulan(2011) & \multicolumn{1}{|c|}{ actual } & \multicolumn{1}{c|}{ forecast } & \multicolumn{1}{c|}{ Error } & \multicolumn{1}{c|}{ \%error } \\
\hline 1 & 59160 & 63844 & 4684 & $7,92 \%$ \\
\hline 2 & 44853 & 45334 & 481 & $1,07 \%$ \\
\hline 3 & 51930 & 59512 & 7582 & $14,60 \%$ \\
\hline 4 & 66429 & 65954 & 475 & $0,72 \%$ \\
\hline 5 & 56052 & 63574 & 7522 & $13,42 \%$ \\
\hline 6 & 72350 & 84610 & 12260 & $16,95 \%$ \\
\hline 7 & 83988 & 82606 & 1382 & $1,65 \%$ \\
\hline 8 & 68855 & 74791 & 5936 & $8,62 \%$ \\
\hline 9 & 82076 & 88299 & 6223 & $7,58 \%$ \\
\hline 10 & 75050 & 80610 & 5560 & $7,41 \%$ \\
\hline 11 & 59483 & 69237 & 9754 & $16,40 \%$ \\
\hline 12 & 70739 & 81174 & 10435 & $14,75 \%$ \\
\hline & & & AFER & $\mathbf{9 , 2 6 \%}$ \\
\hline & & & MSE & $\mathbf{4 9 7 9 8 8 9 5}$ \\
\hline
\end{tabular}

Hasil peramalan untuk tahap uji coba yaitu peramalan jumlah wisatawan 2011 dengan data input: 2009, 2010 dan output: 2011 menunjukan AFER=9,26\% dan $\mathrm{MSE}=49.798 .895$.

\subsection{Peramalan metode Fuzzy Time Series}

\section{Persentase Perubahan Data}

Persentase perubahan jumlah wisatawan digunakan untuk mendefinisikan himpunan semesta U. Untuk mencari nilai perubahan persentase menggunakan rumus $\frac{t_{j}-t_{j-1}}{t_{j-1}} \times 100 \%$, dimana :

$t_{j} \quad=$ jumlah wisatan pada bulan yang diamati

$t_{j-1} \quad=$ jumlah wisatawan pada bulan sebelumnya 
Tabel 2. Persentase Perubahan Data Jumlah Wisatawan 2006-2010

\begin{tabular}{|c|c|c|c|c|c|c|c|c|c|c|c|}
\hline periode & jum & $\%$ & periode & jum & $\%$ & periode & jum & $\%$ & Periode & jum & $\%$ \\
\hline Jan-06 & 6775 & - & Apr-07 & 15046 & $10,44 \%$ & Jul-08 & 33671 & $14,12 \%$ & Okt-09 & 42423 & $-0,41 \%$ \\
\hline Feb-06 & 5848 & $13,68 \%$ & Mei-07 & 14677 & $-2,45 \%$ & Agust-08 & 29418 & $-12,63 \%$ & Nop-09 & 40997 & $-3,36 \%$ \\
\hline Mar-06 & 8518 & $45,66 \%$ & Jun-07 & 20518 & $39,80 \%$ & Sep-08 & 32684 & $11,10 \%$ & Des-09 & 47233 & $15,21 \%$ \\
\hline Apr-06 & 11373 & $33,52 \%$ & Jul-07 & 20288 & $-1,12 \%$ & Okt-08 & 35966 & $10,04 \%$ & Jan-10 & 44366 & $-6,07 \%$ \\
\hline Mei-06 & 9422 & $-17,15 \%$ & Agust-07 & 18030 & $-11,13 \%$ & Nop-08 & 19590 & $-45,53 \%$ & Feb-10 & 33559 & $-24,36 \%$ \\
\hline Jun-06 & 14862 & $57,74 \%$ & Sep-07 & 21170 & $17,42 \%$ & Des-08 & 26343 & $34,47 \%$ & Mar-10 & 43949 & $30,96 \%$ \\
\hline Jul-06 & 12521 & $-15,75 \%$ & Okt-07 & 18977 & $-10,36 \%$ & Jan-09 & 27873 & $5,81 \%$ & Apr-10 & 42768 & $-2,69 \%$ \\
\hline Agust-06 & 12135 & $-3,08 \%$ & Nop-07 & 17757 & $-6,43 \%$ & Feb-09 & 20195 & $-27,55 \%$ & Mei-10 & 50070 & $17,07 \%$ \\
\hline Sep-06 & 14556 & $19,95 \%$ & Des-07 & 22120 & $24,57 \%$ & Mar-09 & 24075 & $19,21 \%$ & Jun-10 & 64827 & $29,47 \%$ \\
\hline Okt-06 & 11201 & $-23,05 \%$ & Jan-08 & 20235 & $-8,52 \%$ & Apr-09 & 30036 & $24,76 \%$ & Jul-10 & 63552 & $-1,97 \%$ \\
\hline Nop-06 & 10758 & $-3,96 \%$ & Feb-08 & 15466 & $-23,57 \%$ & Mei-09 & 34913 & $16,24 \%$ & Agust-10 & 58412 & $-8,09 \%$ \\
\hline Des-06 & 14267 & $32,62 \%$ & Mar-08 & 21593 & $39,62 \%$ & Jun-09 & 44909 & $28,63 \%$ & Sep-10 & 67072 & $14,83 \%$ \\
\hline Jan-07 & 12716 & $-10,87 \%$ & Apr-08 & 21259 & $-1,55 \%$ & Jul-09 & 45401 & $1,10 \%$ & Okt-10 & 62082 & $-7,44 \%$ \\
\hline Feb-07 & 9498 & $-25,31 \%$ & Mei-08 & 22968 & $8,04 \%$ & Agust-09 & 45390 & $-0,02 \%$ & Nop-10 & 54483 & $-12,24 \%$ \\
\hline Mar-07 & 13624 & $43,44 \%$ & Jun-08 & 29505 & $28,46 \%$ & Sep-09 & 42597 & $-6,15 \%$ & Des-10 & 62732 & $15,14 \%$ \\
\hline
\end{tabular}

\section{Himpunan Semesta}

Diperoleh data dengan persentase terbesar dan terkecil yaitu Delta Min $=-45,53 \%$, Delta $\operatorname{Max}=57,74 \%$. Jumlah inverval yang diperoleh adalah 7 dengan menggunakan rumus Sturges kemudian dari seluruh data yang ada dapat dinyatakan himpunan Semesta $U=[-45,53 \%, 57,74 \%]$ dengan lebar masingmasing interval adalah sebagai berikut:

Tabel 3. Frekuensi Kepadatan Data Berdasarkan Distribusi Perubahan Persentase

\begin{tabular}{|c|l|c|c|c|}
\hline Selang & Interval & Data & Sub Interval & Lebar Interval \\
\hline 1 & {$[-45,53 \%,-30,78 \%)$} & 1 & 1 & $14,75 \%$ \\
\hline 2 & {$[-30,78 \%,-16,03 \%)$} & 0 & - & - \\
\hline 3 & {$[-16,03 \%,-1,27 \%)$} & 6 & 1 & $14,75 \%$ \\
\hline 4 & {$[-1,27 \%, 13,48 \%)$} & 20 & 4 & $3,69 \%$ \\
\hline 5 & {$[13,48 \%, 28,23 \%)$} & 9 & 1 & $14,75 \%$ \\
\hline 6 & {$[28,23 \%, 42,98 \%)$} & 11 & 2 & $7,38 \%$ \\
\hline 7 & {$[42,98 \%, 57,74 \%]$} & 12 & 3 & $4,92 \%$ \\
\hline
\end{tabular}

jumlah data terbesar pertama dibagi menjadi empat sub-interval yang sama dengan panjang masing-masing interval 3,69\%. Jumlah data terbesar kedua terdapat pada selang interval $[42,98 \%, 57,74 \%]$ diikuti selang interval $[28,23 \%$, $42,98 \%$ ) kemudian dibagi menjadi tiga dan dua sub-interval yang sama dengan panjang masing-masing interval $4,92 \%$ dan $7,38 \%$. 
Tabel 4. Interval Fuzzy Menggunakan Kepadatan Frekuensi Berdasarkan Pembagian

\begin{tabular}{|c|c|c|c|c|c|c|c|c|c|}
\hline Ling & Interval & N.Tengah & Lebar & Koef & Ling & Interval & N.Tengah & Lebar & Koef \\
\hline A01 & {$[-45,53 \%,-23,40 \%)$} & $-34,47 \%$ & $22,13 \%$ & a & A07 & {$[13,48 \%, 28,23 \%)$} & $20,86 \%$ & $14,75 \%$ & a7 \\
\hline A02 & {$[-23,40 \%,-1,27 \%)$} & $-12,34 \%$ & $22,13 \%$ & a2 & A08 & {$[28,23 \%, 35,61 \%)$} & $31,92 \%$ & $7,38 \%$ & a8 \\
\hline A03 & {$[-1,27 \%, 2,41 \%)$} & $0,57 \%$ & $3,69 \%$ & a3 & A09 & {$[35,61 \%, 42,98 \%)$} & $39,30 \%$ & $7,38 \%$ & a9 \\
\hline A04 & {$[2,41 \%, 6,10 \%)$} & $4,26 \%$ & $3,69 \%$ & a4 & A10 & {$[42,98 \%, 47,90 \%)$} & $45,44 \%$ & $4,92 \%$ & a10 \\
\hline A05 & {$[6,10 \%, 9,79 \%)$} & $7,95 \%$ & $3,69 \%$ & a & A11 & {$[47,90 \%, 52,82 \%)$} & $50,36 \%$ & $4,92 \%$ & a11 \\
\hline A06 & {$[9,79 \%, 13,48 \%)$} & $11,63 \%$ & $3,69 \%$ & a6 & A12 & {$[52,82 \%, 57,74 \%]$} & $55,28 \%$ & $4,92 \%$ & a12 \\
\hline
\end{tabular}

Setelah pembagian interval dilakukan pada masing-masing interval dengan menggunakan variabel linguistik dari A1 sampai A12 dan nilai tengah merupakan nilai tengah dari jarak masing-masing interval dan diberi nama koefisien a1 sampai a12. Nilai tengah ini akan digunakan pada tahap defuzzyfikasi. Dari hasil defuzzyfikasi diperoleh nilai AFER 6,79\% dan MSE 6.988.536 ini menunjukkan bahwa dari rentang nilai AFER 0\% - 100\% diperoleh nilai AFER sebesar 6,79\%. FLRG terbentuk dari Left-Hand Side(LHS) dan Right-Hand Side(RHS) pada fuzzy set yang sudah ada. LHS merupakan fuzzy set yang berada pada sisi kiri dan RHS merupakan fuzzy set yang berada pada sisi kanan. Pada penentuan FLRG ini yang menjadi LHS adalah semua fuzzy set yang urutannya sama dengan urutan fuzzy set yang sudah ditentukan sebelumnya dan yang menjadi RHS akan dimulai pada fuzzy set pada LHS yang kedua. FLRG dinotasikan dengan LHS $\rightarrow$ RHS dimana ini menunjukkan bahwa fuzzy set pertama menuju ke fuzzy set kedua, fuzzy set kedua menuju ke fuzzy set ketiga, fuzzy set ketiga menuju ke fuzzy set keempat dan seterusnya sampai LHS terakhir

\section{Hasil Peramalan Bulan Januari - Desember 2011 Fuzzy Time Series}

Data yang digunakan untuk menghitung persentase perubahan yaitu 12 data sebelumnya, alasannya karena jika terlalu banyak data yang digunakan maka periode waktu akan semakin jauh sehingga pengaruh yang diberikan terhadap nilai yang akan diramal tidak signifikan. Untuk mencari nilai perubahan persentase pada Bulan Januari yaitu dengan menghitung masing-masing frekuensi FLRG dan diberikan bobot pada masing-masing FLRG kemudian nilai proporsi frekuensi FLRG dikalikan dengan nilai logaritma basis 2 bobot Fibonacci, selanjutnya proporsi masing-masing proporsi frekuensi yang sudah dikalikan dengan logaritma basis 2 bobot Fibonacci, nilai proporsi tersebut dikalikan dengan nilai tengah sesuai dengan variable lingustik LHS, Sehingga diperoleh persentase nilai peramalan maing-masing FLRG. Nilai perubahan persentase yang telah diperoleh akan dikembalikan ke dalam nilai peramalan dengan menggunakan rumus : Data Sekarang $=(\%$ perubahan $\times$ Data Sebelum $)+$ Data Sebelum

Dari nilai-nilai tersebut dapat diperoleh error dari masing-masing bulan peramalan dengan cara mencari selisih antara nilai peramalan dengan nilai aktual. 
Error yang telah diperoleh digunakan untuk mencari nilai AFER dan MSE untuk peramalan metode Fuzzy Time Series.

Tabel 5. Hasil Peramalan FTS Tahun 2011

\begin{tabular}{|r|r|r|r|r|r|}
\hline \multicolumn{1}{|c|}{ Time Index } & \multicolumn{1}{c|}{ Actual } & \% Forecast & \multicolumn{1}{c|}{ Forecast } & \multicolumn{1}{l|}{ Error } & \multicolumn{1}{c|}{ Error $^{\wedge} \mathbf{2}$} \\
\hline Jan 2011 & 59160 & $-2,24 \%$ & 61326 & 2166 & 4691651 \\
\hline Feb 2011 & 44853 & $2,69 \%$ & 62978 & 18125 & 328503893 \\
\hline Mar-11 & 51930 & $-0,16 \%$ & 62871 & 10941 & 119705592 \\
\hline Apr 2011 & 66429 & $2,84 \%$ & 64662 & 1767 & 3121963 \\
\hline Mei-11 & 56052 & $2,21 \%$ & 66094 & 10042 & 100833540 \\
\hline Jun-11 & 72350 & $3,69 \%$ & 68537 & 3813 & 14541245 \\
\hline Jul-11 & 83988 & $2,38 \%$ & 70169 & 13819 & 190956170 \\
\hline Agust-11 & 68855 & $3,43 \%$ & 72576 & 3721 & 13846575 \\
\hline Sep-11 & 82076 & $2,04 \%$ & 74061 & 8015 & 64241084 \\
\hline Okt-11 & 75050 & $3,40 \%$ & 76581 & 1531 & 2342795 \\
\hline Nop-11 & 59483 & $1,78 \%$ & 77944 & 18461 & 340815748 \\
\hline Des-11 & 70739 & $2,18 \%$ & 79650 & 8911 & 79397914 \\
\hline & & & & AFER & $\mathbf{1 4 , 0 2 \%}$ \\
\hline & & & & MSE & $\mathbf{1 0 5 2 4 9 8 4 8}$ \\
\hline
\end{tabular}

Dari tabel 5 diperoleh nilai AFER sebesar 14,02\% dan MSE sebesar 105.249.848.

\subsection{Komparasi Metode ANFIS dengan Fuzzy Time Series}

Hasil peramalan yang untuk metode ANFIS dibandingkan dengan metode Fuzzy Time Series menunjukan bahwa metode ANFIS memiliki nilai AFER dan MSE yang lebih kecil dibandingkan dengan metode Fuzzy Time Series. Peramalan dengan menggunakan metode ANFIS diperoleh AFER sebesar 9,26\% dan MSE sebesar 49.798.895 sedangkan peramalan dengan menggunakan metode Fuzzy Time Series diperoleh AFER sebesar 14,02\% dan MSE sebesar 105.252.076.

\section{Kesimpulan}

Kesimpulan yang didapat adalah:

1. Peramalan jumlah wisatawan Australia ke Bali Tahun 2011 dengan metode ANFIS adalah sebesar 859.545. Untuk tingkat keakurasian hasil peramalan diperoleh nilai AFER sebesar 9,26\% dan MSE sebesar 49.798.895. Peramalan metode Fuzzy Time Series adalah sebesar 837.449. Untuk tingkat keakurasian hasil peramalan diperoleh nilai AFER sebesar 14,02\% dan MSE sebesar 105.252.076.

2. Melihat nilai AFER dan MSE yang diperoleh dari hasil peramalan kedua metode, menunjukan bahwa metode ANFIS memiliki tingkat kesalahan yang lebih kecil dibandingkan dengan metode Fuzzy Time Series pada kasus peramalan jumlah wisatawan Australia ke Bali Tahun 2011. 


\section{Daftar Pustaka}

[1] Dinas Pariwisata Bali. 2010. Jumlah Wisatawan Mancanegara ke Bali http://www.tourism.baliprov.go.id/informasi/2010/12/statistics diakses 20 November 2011

[2] Jilani, T. A., S. M. A. Burney, C.Ardil. 2007. "Fuzzy Metric Approach for Fuzzy Time Series Forecasting based on Frequency Density Based Partitioning", Proceedings of World Academy of Science, Engineering and Technology, Vol.34 : pp.333-338

[3] Kusumadewi, Sri. 2003. Artificial Inteligence (Teknik dan Aplikasi). Yogyakarta: Graha Ilmu

[4] Stevenson, Meredith and John E. Porter. 2009. "Fuzzy Time Series Forecasting Using Percentage Change as the Universe of Discourse". Proceedings of World Academy of Science, Engineering and Technology, Vol 55. 